\title{
Fenologia do pau-rosa (Aniba duckei Kostermans), Lauraceae, em floresta primária na Amazônia Central
}

BIBLIOTECA do INPA

\author{
Luís Mauro Sampaio Magalhães (") \\ Jurandyr da Cruz Alencar ( ${ }^{*}$ )
}

\begin{abstract}
Resumo
Os autores estudam as diversas fases fenológicas (floração, frutificação e mudança foliar) de Pau-rosa (Aniba duckei Kostermans), Lauraceae, em floresta primária tropical, próxima a Manaus. Foi observado o comportamento desta espécie e relacionado com as demais existentes na mesma área. A espécie apresenta mudança foliar anualmente, o que nāo acontece para as fases de floração e frutificação. Quando presente, a floração ocorreu sempre no período mais úmido. Dadas a irregularidade na floração - frutificação, e a grande predação dos frutos por Psitacídeos, verificada pelos autores, o fornecimento regular de sementes fica comprometido, havendo necessidade de pesquisarem-se novas formas de propagação para a espécie.
\end{abstract}

\section{INTRODUÇÃo}

Espécies florestais nativas amazônicas devem ser pesquisadas de modo a permitir a reposição adequada do material explorado nestas áreas e evitar o estrangulamento no fornecimento destes recursos. Para a recomposição de matas exploradas, uma das dificuldades que se encontra é a falta de fornecimento adequado de sementes, ocasionado principamente pela inexistência de informações acerca das fenofases destas essências (floração, frutificação e mudança foliar). Diversos autores têm-se ocupado do estudo de fenofases de matas tropicais. Fournier (1976), em trabalhn sobre floresta tropical úmida na Costa Rica, observou que as espécies que lá ocorrem apresentam o pico da floração durante a estação seca e começo da estação chuvosa. Daubenmire (1972), também, observou, no noroeste da Costa Rica, a maior ocorrência de floração no período seco. Em trabalho realizado em floresta tropical úmida de terra firme, na Amazônia, Araujo (1970) observou que o maior índice de floração, em 36 espécies florestais amazônicas, ocorreu no período seco. Alencar et al. (1979) também obser- varam este fenômeno e apontaram a existência de espécies com fenofases irregulares.

O pau-rosa (Aniba duckei Kostermans), da família das Lauráceas, tem grande valor econômico devido à extração do linalol a partir do óleo destilado de sua madeira ou folhas, produto bastante procurado no mercado nacional e internacional pelo seu uso em perfumaria como fixador. Esta essência apresenta também um bom potencial silvicultural, com experimentos indicando bom crescimento em plena abertura (Vieira, 1970) e sob sombra de floresta primária economicamente explorada (Alencar \& Fernandes, 1978) .

Os objetivos deste trabalho foram: pesquisar as diversas fenofases de A. duckei em floresta primária; possibilitar a racionalização na coleta de sementes; fornecer maiores informações acerca da biologia da espécie, bem como da interação desta com o ambiente.

\section{ÁREA DE ESTUDO}

Este estudo foi desenvolvido na área da Reserva Florestal Ducke, situada no $\mathrm{Km} 26$ da Rodovia AM-010, latitude $03^{\circ} 08^{\prime}$ Sul e longitude $60^{\circ} 02^{\prime}$ Oeste. O clima desta área, segundo Ribeirc (1976), é do tipo Afi, de acordo com a classificação climatológica de Köppen: clima tropical praticamente sem inverno, a temperatura média para o mês mais frio nunca é inferior a $18^{\circ} \mathrm{C}$, com chuvas durante todo o ano, acusando isotermia, uma vez que as oscilações anuais de temperatura média não chegam a $5^{\circ} \mathrm{C}$. Dados referentes às observações mensais de precipitação, insolação, temperaturas máximas e mínimas absolutas, além da umidade relativa do ar, no período de 1967 a 1978, encontram-se em Ribeiro (1978).

O tipo de vegetação da área é de floresta tropical úmida de terra firme.

(") - Instituto Nacional de Pesquisas da Amazônia, Manaus. 
MATERIAL E MÉTODOS

Aniba duckei atinge até $30 \mathrm{~m}$ de altura em floresta primária e ocorre naturalmente ao sul e ao norte do rio Amazonas. Tem casca pardicavermelhada, folhas semicoriáceas, lisas e in. florescência em panículas multifloras delicadas. As flores são ferrugíneas e o fruto é uma drupa, de 2 a $3 \mathrm{~cm}$ de comprimento, com cúpula bastante espessa.

No ano de 1967, foi feita a marcação e mapeamento de vinte árvores de $A$. duckei para estudo, com diâmetro à altura do peito acima de $15 \mathrm{~cm}$. Foram feitas observações mensais no período de 1968 a 1978 , com auxílio de um binóculo tipo Zenith $8 \times-14 \times 50$, e o registro das seguintes fases:

Floração: 1 - Botões florais ou inflorescên. cia presente; 2 - Floração adiantada ou árvore totalmente florada; 3 - Floração terminando ou terminada.

Frutificação: 4 - Frutos novos aparecendo; 5 - Frutos maduros presentes; 6 - Frutos maduros caindo e sementes dispersas.

Mudança foliar: 7 - Árvore com pouca folha ou desfolhada; 8 - Folhas novas aparecendo; 9 - Maioria das folhas, novas ou totalmente novas; e 10 - Copa completa com folhas veIhas. Para cada uma destas fases, determinou-se a freqüência mensal de árvores que apresentavam o fenômeno. Para a mudança foliar, consideraram-se as fases 7,8 e 9 em conjunto e a fase $10 \mathrm{em}$ separado. A floração incluiu suas três fases (1, 2 e 3) e, na frutificação, consideraram-se as fases 4 e 5 agrupadas, separadas da fase 6 (Fig. 1).

Numa tentativa de mostrar graficamente a relação entre os eventos climáticos e os fenológicos do Pau-rosa, é apresentada na Fig. 2 a somatória dos totais mensais das variáveis climáticas (precipitação, insolação, umidade relativa do ar e temperaturas máximas e mínimas absolutas) no período de 1968 a 1978, cujas curvas podem ser comparadas com as das freqüências de floraçăo (Fases 1, 2 e 3), frutificação (Fases 4 e 5) e mudança foliar (Fases 7, 8 e 9) na Fig. 3.

\section{Resultados}

A Fig. 1 mostra a periodicidade anual que existe para mudança foliar nesta espécie. No período de menor precipitação (de julho a dezembro), aumenta o número de indivíduos com poucas folhas, desfolhadas ou com folhas novas. A medida que se aproxima a épo. ca mais úmida (novembro a maio), este número cai para pouca ou nenhuma árvore nesta fase e aumenta o número de árvores com folhas velhas. A. duckei não floresce anualmente, pois, após uma boa freqüência de indivíduos florando em 1968, poucas árvores apresentaram este evento durante um período de sete anos. Somente no ano de 1976 ocorreu novamente boa floração com quinze das vinte árvores apresentando botões florais. Quando presente, a floração ocorreu sempre no periodo de maior precipitação (de novembro a maio). Pode ser observado também que, apesar de ocorrer floração em algumas árvores nos anos de 1971, 1972 e 1973, não houve frutificação neste período. Dos anos observados, somente em cinco ocorreu frutificaçăo (1968, 1969, 1976, 1977 e 1978), com um período de seis anos sem ocorrer este evento. Este, quando presente, tinha seu início sempre na época de chuvas, se estendendo por um ano

Convém destacar que, no ano em que ocor. reu o maior número de árvores apresentando mudança foliar (em 1976), este foi anterior ao ano de maior freqüência na floração. Logo após esta floração e com o início da frutificação, a freqüência de árvores mudando suas folhas, caiu para a mais baixa de todo o período observado. A Fig. 1 mostra também que sempre que ocorreu fioração, esta foi precedida de um pico na curva de freqüência de mudança foliar.

Nas Figs. 2 e 3, pode ser verificado que a curv a de mudança foliar tem um aumento na mesma época em que aumenta a insolação e as temperaturas máximas e mínimas absolutas, no mês de julho, seguindo alta até outubro. A curva de floraçäo aumenta, a partir do mês de outubro com um pico na época de chuvas (janeiro), chegando novamente a zero no mês de maio. A frutificação tem maior freqüếncia também no período de chuvas com um pico máximo no mês de março. 

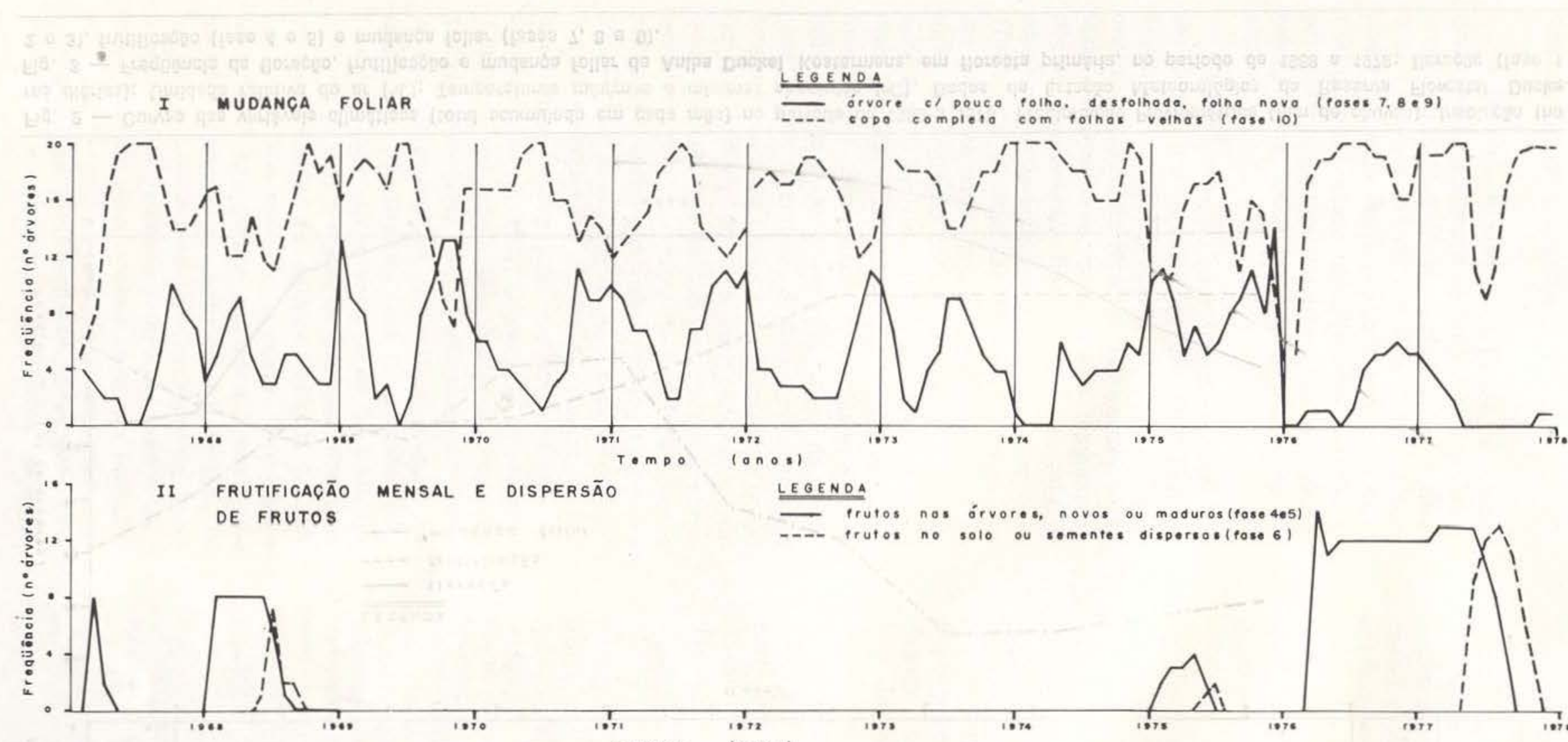

MENSAL E DISPERSÃO

Ompo ianosing

LEGENOA

- trutos nos órvores, novos ou maduros (fose 4e5) -.- Trutes no solo ou sementes dispersos (tose 6 )
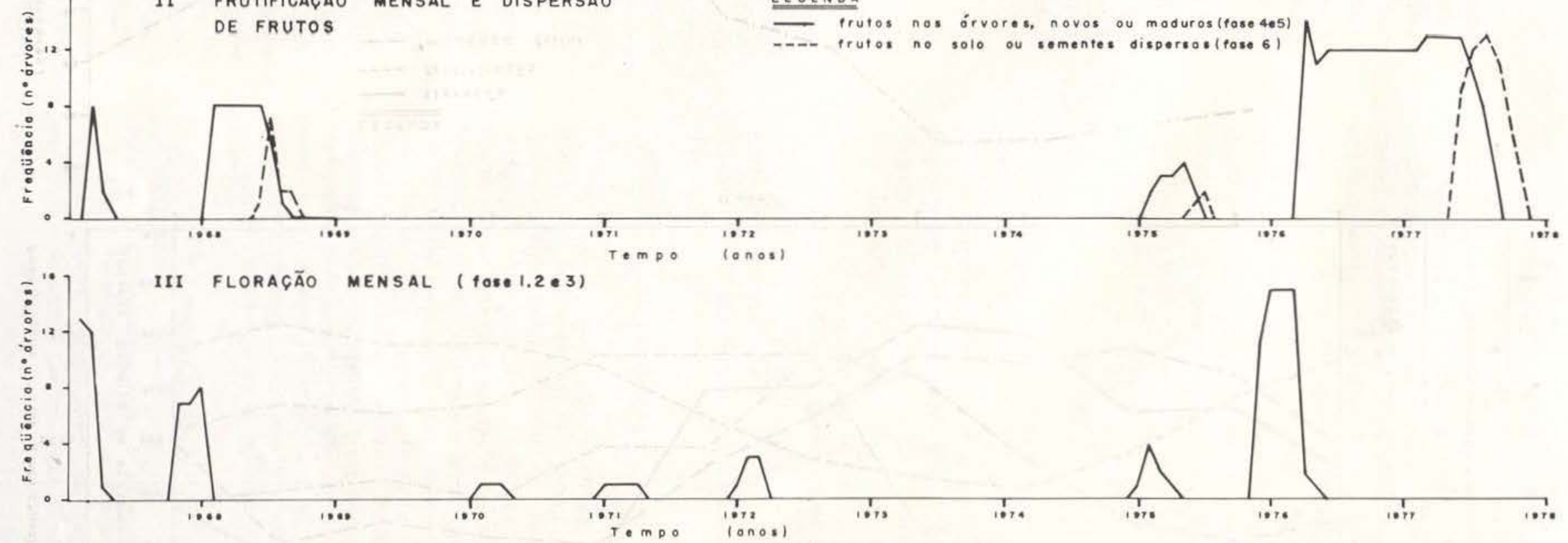

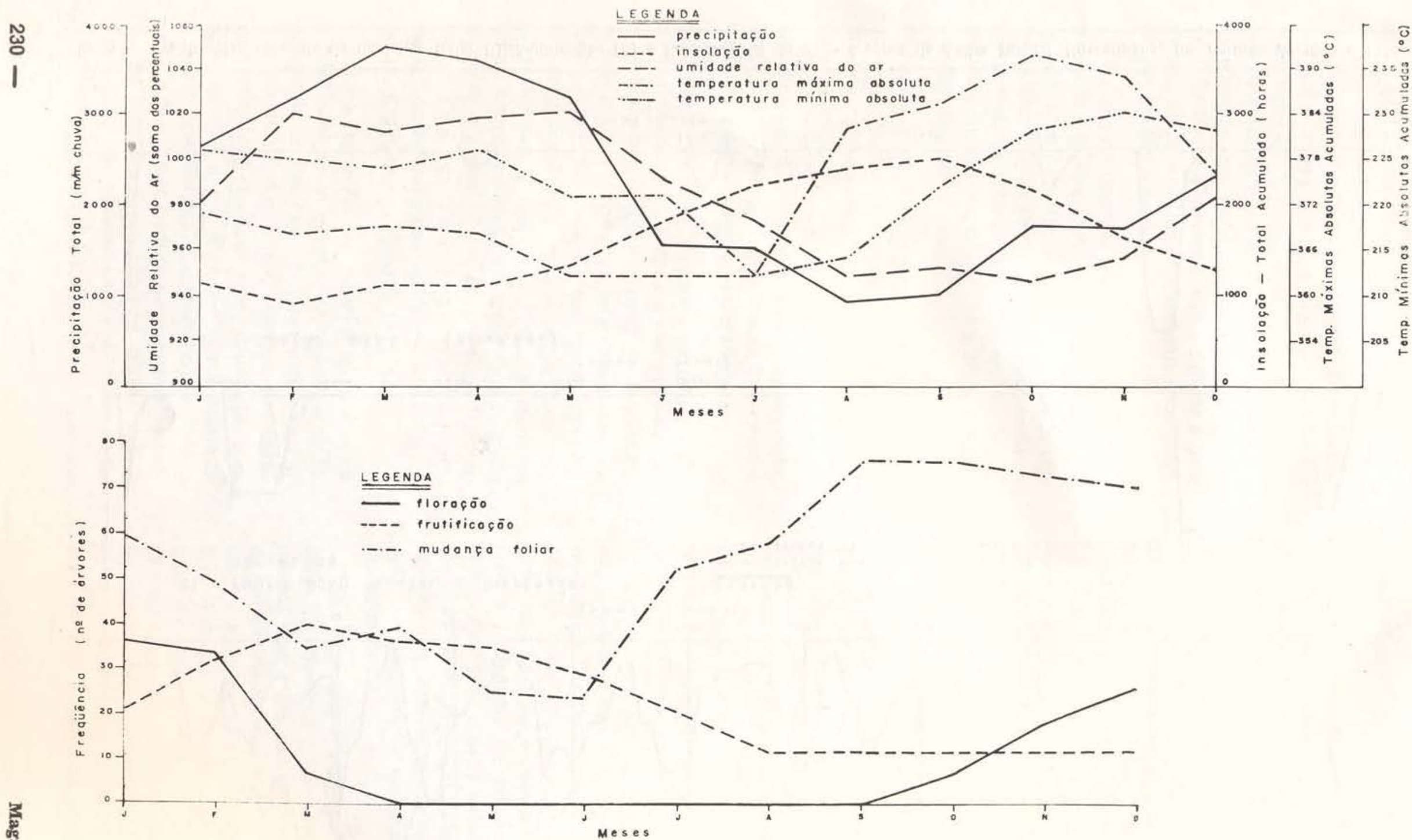

Fig. 2 - Curvas das variáveis climáticas (total acumulado em cada mês) no periodo de 1968 a 1978. Precipitação Pluviométrica (mm de chuvass): Insolação (horas diárias); Umidade relativa do ar $(\%)$; Temperaturas máximas e mínimas absolutas $\left({ }^{\circ} \mathrm{C}\right)$. Dados da Estação Meteorológica da Reserva Florestal Ducke. Fig. 3 - Frequeência da floraçăo, frutificação e mudança foliar de Aniba Duckel Kostermans, em floresta primária, no período de 1968 a 1978; floraçāo (fase 1 2 e 3), frutificaçăo (fase 4 e 5 ) e mudança foliar (fases 7,8 e 9). 


\section{CONCLUSÕES E DISCUSSÃo}

A fase de mudança de folhas teve ocorrência anual e sempra durante o período seco, o que segundo Alencar et al. (1979) acontece com a maioria das vinte e sete espécies estudadas por eles nesta região. Longman \& Jenik (1974), em estudo de florestas estacionais perenifólias, citam também que os brotos emergem na época seca, antes do início das chuvas.

Esta espécie, ao contrário da maioria das estudadas por Alencar et al. (1979) nesta mesma área, não apresenta floração e frutificação anuais. Este fato foi, entretanto, obser. vado pelos autores, que relatam também espécies que tiveram floração em intervalo de dois anos e floração irregular, com uma delas (Tachigalia paniculata) florescendo duas vezes em doze anos. Isto parece indicar que fatores de interação com o biótopo e fatores fisiológicos, além dos climáticos, estão envolvidos. Frankie et al. (1974) discutem a hipótese de que, em certas espécies tropicais, esta irregularidade poderia ser uma "fuga" da predação de suas sementes. A. duckei sofre intensa predação de seus frutos por pássaros do grupo dos Psitacídeos. por nós verificada, e a irregularidade de frutificação poderia estar correlacionada com o controle de população destes pássaros. Como algumas espécies estudadas por Alencar et al. (1979), A. duckei apresentou floração sempre na época de chuvas e não temos hoje indicação do que ocasiona este fenômeno. Alvin (1966a) afirma que, em regiões tropicais, as condições fotoperiódicas são sempre favoráveis para a diferenciação floral, já que nestas regiōes não existem grandes variaçoes na temperaturá para os períodos úmidos ou secos. Uma observação bastante importante é que o início da floração, nos anos em que esta ocorre, sempre coincide ou vem logo após um máximo na curva de mudança de folhas. Isto parece confirmar a afirmação de Alvin (1966b) que, estudando a floração de coco, diz existir uma relação aparente entre a emissão de folhas e a floração, com o estimulo desta última originando-se em mecanismoŝ hormonais, a partir de folhas novas. A ocorrência de frutificação nesta espécie teve início sempre na época de chuvas seguindo o que ocorre na maioria de espécies desta área (Alencar et al., 1979). Apesar da ocor. rência de floração em algumas árvores em três anos seguidos, não foi observada frutificação destes indivíduos neste período, fenômeno provavelmente ocasionado por fatores anteriormente discutidos. Parece-nos que, dadas a irregularidade na floração-frutificação $e$ a grande predação de frutos sofrida por $A$. duckei, será bastante difícil obtermos hoje boa quantidade de sementes, sendo recomendável pesquisar novos meios de propagação, do tipo assexuado, uma vez que já sabemos que a espécie pode ser propagada vegetativamente (Rodrigues, 1962; Vieira, 1972).

\section{Agradecimentos}

Os autores agradecem a colaboração do Engenheiro Agrônomo Vivaldo Campbeli de Araujo e ao corpo técnico da Divisão de Botânica do INPA, representada pelo Dr. Wiiliam Rodrigues, pelo auxílio na identificação do material botânico. Queremos também ressaltar e agradecer a grande dedicação e empenho dos auxiliares Lourival Quintiliano dos Reis e José Aluísio da Costa Souza nos trabalhos realiza. dos.

\section{SUMMARY}

The authors study the phenology (flowering, fruiting and leaf changing) of a natural population of Pau-rosa (Aniba duckei Kostermans), Lauraceae, in a tropical rain forest near Manaus. The species behaviour and its relation with other species of this same area was observed. This species presents annual leaf changing. but this annual phenomenon does not occur in flowering and fruiting. When present, flowering has always occured during the wet season. Because of the flowering irregularity, and the great fruit predation by Psitacideae birds observed by the authors, the regular seed supply becomes difficult and for this reason research concerning new methods of vegetative propagation of this species is required.

\section{BIBLIOGRAFIA}

Alencar, J.C.; Almeida, R.A. \& Fernandes, N.P. 1979 - Fenologia de Espécies Florestais em Floresta Tropical Úmida de Terra Firme na Amazônia Central. Acta Amazonica, $9(1)$ : 163-198. 
Alencar, J.C. \& Fernandes, N.P.

1978 - Desenvolvimento de árvores nativas em ensaios de espécies. 1 - Pau-rosa (Aniba duckei Kostermans). Acta Amazonica, 8(4): 523-541.

Alvin, P.T.

1966a - Fatores que controlam a floraçăo do cafeeiro. Centro de Pesquisas do Cacau. Itabuna - Bahia. 18 p. mimeografado.

$1966 \mathrm{~b}$ - Factors affecting flowering of the cocoa tree. Cocoa Grower's Bulletin, (7) : 15-19.

Araujo, V.C.

1970 - Fenologia de essências florestais amazônicas. I - Boletim do INPA, (4) $25 \mathrm{p}$.

DAUBENMIRE, $R$.

1972 - Phenology and other characteristics of Tropical Semi-Deciduous Forest in North - Western Costa Rica. Journal of Ecology. $60(1): 147-170$

FOURNIER, L.A.

1976 - Observaciones fenológicas en el bosque húmedo de premontano de San Pedro de Montes de Oca, Costa Rica. Turrialba, 26(1) : $54-59$.

Frankie, G.W.; BAKer, H.G. \& Opler, P.A.

1974 - Comparative phenological studies of trees in Tropical wet and dry forests in Lowlands of Costa Rica. Journal of Ecology, 62(3) : 881-919.

LONGMAN, K.A. \& JeNIK, J,

1974 - Tropical forest and its environment. Tropical Ecology Series. 196 p. London.

RIBEIRO, M.N.G.

1976 - Aspectos climatológicos de Manaus. Acta Amazonica, 6(2) : 229-233.

1978 - Boletim Meteorológico - Estação Meteo. rológica da Reserva Ducke. Anos de 1965 a 1978. Mimeografado.

RODRIGUES, W.A.

1962 - Multiplicação vegetativa de Pau-rosa por estaquia. Ciência e Cultura, Resumo da XIV Reunião Anual da SBPC : 44.

VIEIRA, A.N.

1970 - Aspectos silviculturais do Pau-rosa (Aniba duckei Kostermans). I - Estudos preliminares sobre o incremento volumétrico. Boletim do INPA (14) $15 \mathrm{p}$.

1972 - Aspcetos silviculturais do Pau-rosa (Aniba duckei Kostermans). II - Estudos sobre métodos de propagação. Acta Amazonica, 2(1) : 51-58.

(Aceito para publicação em 29/05/79) 